\title{
NEW COPOLYAMIDES CONTAINING AZOBENZENE GROUPS AND DIFFERENT DIACID AND DIAMINE IN THE MAIN CHAIN: SYNTHESIS AND CHARACTERIZATION
}

\author{
KHALIL FAGHIHI ${ }^{1 *}$, MEISAM SHABANIAN², LEILY GHADIRY ${ }^{1}$ \\ ${ }^{\prime}$ Polymer Research Laboratory, Department of Chemistry, Faculty of Science, Islamic Azad University, Arak Branch, Arak, Iran. \\ 2 Yang Researchers Club, Islamic Azad University, Arak Branch, Arak, Iran \\ (Received: July 21, 2009 - Accepted: January 21, 2010)
}

\begin{abstract}
A new series of copolyamides CoPAs 7a-f were synthesized through the direct polycondensation reaction of 4,4'-azobenzenedicarboxylic acid $\mathbf{1}$ with 1,5-naphthalenediamine 2, 3,4-diaminobenzophenone $\mathbf{3}$ in the presence of adipic acid $\mathbf{4}$, fumaric acid $\mathbf{5}$ and terephthalic acid $\mathbf{6}$ as a second diacid in a medium consisting of N-methyl-2-pyrrolidone, triphenyl phosphate (TPP), calcium chloride and pyridine. The obtained polymers were characterized by means of FT-IR spectroscopy, elemental analyses and inherent viscosity. These CoPAs were highly soluble in polar aprotic solvents such as $N, N$-dimethylacetamide (DMAc), $N, N$-dimethylformamide (DMF), dimethyl sulfoxide (DMSO), $N$-methyl-2-pyrrolidone (NMP) and other solvents such as sulfuric acid. Thermal properties of the CoPAs $7 \mathbf{c}, \mathbf{7 d}$ and $\mathbf{7 e}$ were investigated using thermal gravimetric analysis (TGA and DTG).
\end{abstract}

Key word: Copolymers; Azobenzene; Direct polycondensation, High-performance polymers

\section{INTRODUCTION}

Aromatic polyamides possess excellent mechanical properties and thermal stability; however, they are difficult to process because of their limited solubility and to high glass transition ( $\mathrm{T}_{\mathrm{g}}$ ) or melt temperature due to chain stiffness and intermolecular hydrogen bonding between amide groups [1]. The processing of these thermoplastic polymers has been greatly hindered because they lack softening or melting behavior at usual processing temperature, and they tend to degrade before or at the softening temperature [2]. Several attempts have been made in order to diminish the $\mathrm{T}_{\mathrm{g}}$ or melting temperature of aromatic polyamides to make them processable. One of the used methodologies has been the introduction of linked and flexible bridging units [3-6] into the polymers chain.

Also, synthesis and properties of polymeric materials containing deferent chromophores covalently attached to the polymer backbone have attracted increasing interest in the recent years, not only for their photophysical peculiarities but also for their applications [7-10]. Seeing the great versatility of polyurethanes and their special properties, various monomeric and polymeric materials carrying azoaromatic chromophores were prepared and their photobehavior was studied considering the development of the new photochromic, nonlinear optical, liquid-crystal or biological systems [11-13].

In this article six new CoPAs 7a-f were synthesized through the direct polycondensation reaction of 4,4'-azobenzenedicarboxylic acid 1 with 1,5-naphthalenediamine 2, 3,4-diaminobenzophenone 3 in the presence of adipic acid 4, fumaric acid $\mathbf{5}$ and terephathalic acid $\mathbf{6}$ as a second diacid in a medium consisting of $N$-methyl-2-pyrrolidone, triphenyl phosphite, calcium chloride and pyridine.

\section{EXPERIMENTAL}

\section{Materials}

1,5-Naphthalenediamine 2, 3,4-diaminobenzophenone 3, adipic acid 4, fumaric acid 5, terephthalic acid $\mathbf{6}$, triphenyl phosphite, $N$-methyl-2-pyrrolidone and pyridine were purchased from Merck Chemical Company and used without previous purification. Also commercially available calcium chloride $\left(\mathrm{CaCl}_{2}\right)$ was purchased from Merck Chemical Company and dried under vacuum at $150^{\circ} \mathrm{C}$ for 6 h. $4,4^{\prime}$-azobenzenedicarboxylic acid $\mathbf{1}$ was prepared from 4-nitrobenzoic acid.

Techniques

Fourier transform infrared (FT-IR) spectra were recorded on Galaxy series FTIR 5000 spectrophotometer (England) as $\mathrm{KBr}$ pellets. Vibrational transition frequencies are reported in wave number $\left(\mathrm{cm}^{-1}\right)$. Band intensities are assigned as weak (w), medium (m), shoulder (sh), strong (s) and broad (br). Inherent viscosities were measured by a standard procedure by using a Technico Regd Trad Merk Viscometer. Thermal Gravimetric Analysis (TGA and DTG) data for polymers were taken on a Mettler TA4000 System under $\mathrm{N}_{2}$ atmosphere at a rate of $10^{\circ} \mathrm{C} / \mathrm{min}$. Elemental analyses were measured in Arak Petrochemical
Company laboratories, Arak, Iran.

\section{Monomer synthesis}

Synthesis of 4,4'-azobenzenedicarboxylic acid $\mathbf{1}$

This compound was prepared according to our previous works [14].

\section{Polymer synthesis}

Into a $100 \mathrm{~mL}$ round-bottomed flask were placed a mixture of $4,4^{\prime}$-azobenzenedicarboxylic acid $1(0.16 \mathrm{mmol})$, second diacid 4,5 or $\mathbf{6}(0.16 \mathrm{mmol})$, diamine 2 or $3(0.32 \mathrm{mmol}), 0.10 \mathrm{~g}$ of calcium chloride, $0.84 \mathrm{~mL}$ of triphenyl phosphite, $0.2 \mathrm{~mL}$ of pyridine and $3 \mathrm{~mL}$ NMP. The mixture was heated for $1 \mathrm{~h}$ at $60^{\circ} \mathrm{C}, 2 \mathrm{~h}$ at $90{ }^{\circ} \mathrm{C}$ and then refluxed at $130{ }^{\circ} \mathrm{C}$ for $8 \mathrm{~h}$ until a viscose solution was formed. Then it was cooled to room temperature and $30 \mathrm{~mL}$ of methanol was added to reaction mixture. The precipitate was formed, filtered off and washed with methanol. The resulting polymers 7a-f were dried under vacuum.

\section{RESULTS AND DISCUSSION}

\section{Polymer synthesis}

Copolyamides 7a-f were synthesized by the direct solution polycondensation reaction of an equivalent of diacid $\mathbf{1}$ as a first diacid, an equivalent of diacid 4,5 or $\mathbf{6}$ as second diacid, with two equivalents of aromatic diamines 2 or $\mathbf{3}$ using TPP, NMP and pyridine as condensation agents (Scheme 1). The polymerization yield and some physical properties of these CoPAs 7a-f are given in Table 1. All of the polymers were obtained in good yields and had inherent viscosities between $0.31-0.58 \mathrm{dLg}^{-1}$.

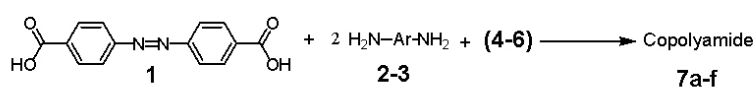

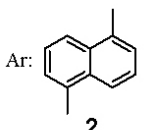
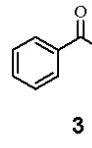<smiles>CCCC</smiles>

4<smiles>O=C(O)C=CC(=O)O</smiles>
5<smiles>CCCCCCC(=O)O</smiles><smiles>O=C(O)c1ccc(C(=O)O)cc1</smiles>

Scheme 1. Synthesis of CoPAs 7a-f 
Table 1: Yield and some physical properties of CoPAs 7a-f

\begin{tabular}{|c|c|c|c|c|c|}
\hline Polymer & Second Diacid & Diamine & Yield (\%) & $\eta_{\text {inh }}(\mathrm{dl} / \mathrm{g})^{\mathrm{a}}$ & Color $^{\mathrm{b}}$ \\
\hline $\mathbf{7 a}$ & Adipic acid (4) & 1,5-Naphthalenediamine (2) & 91 & 0.31 & $\mathrm{R}$ \\
$\mathbf{7 b}$ & Fumaric acid (5) & 1,5-Naphthalenediamine (2) & 84 & 0.36 & $\mathrm{R}$ \\
$\mathbf{7 c}$ & Terephthalic acid (6) & 1,5-Naphthalenediamine (2) & 88 & 0.55 & $\mathrm{~B}$ \\
$\mathbf{7 d}$ & Adipic acid (4) & 3,4-Diaminobenzophenone (3) & 87 & 0.30 & $\mathrm{C}$ \\
$\mathbf{7 e}$ & Fumaric acid (5) & 3,4-Diaminobenzophenone (3) & 89 & 0.44 & $\mathrm{R}$ \\
$\mathbf{7 f}$ & Terephthalic acid (6) & 3,4-Diaminobenzophenone (3) & 86 & 0.58 & $\mathrm{DR}$ \\
\hline
\end{tabular}

${ }^{a}$ Measured at a concentration of $0.5 \mathrm{~g} / \mathrm{dL}$ in DMF at $25^{\circ} \mathrm{C}$.

b, $\mathrm{B}=$ Brown, $\mathrm{C}=$ Cream, $\mathrm{DR}=$ Dark Red, $\mathrm{R}=$ Red

\section{Polymer characterization}

These polymers were confirmed to be CoPAs by using FTIR spectroscopy and elemental analyses. These polymers had an absorption band around 1660 $\mathrm{cm}^{-1}$ due to amide and benzophenone (PA 7d-f) carbonyl groups. It is possible to see a peak around $1425 \mathrm{~cm}^{-1}$ related to azo groups $(-\mathrm{N}=\mathrm{N}-)$ in the polymer backbone. Also absorption band of amide group appeared around $3235 \mathrm{~cm}^{-1}$ (N-H stretching). All of the CoPAs showed similar patterns that summarized in Table 2. The elemental analysis values of the resulting polymers were in good agreement with the calculated values for the proposed structures (Table 3 ).

Table 2 FT-IR characterization of CoPAs 7a-f

\begin{tabular}{|c|c|}
\hline Polymer & Spectra data $\left(\mathrm{n}, \mathrm{cm}^{-1}\right)$ \\
\hline $7 \mathbf{a}$ & $\begin{array}{l}3230(\mathrm{~m}), 2990(\mathrm{~m}), 1662(\mathrm{~s}), 1575(\mathrm{w}), 1428(\mathrm{~m}), 1308(\mathrm{~m}), \\
1230(\mathrm{~m}), 1130(\mathrm{~m}), 826(\mathrm{w}), 776(\mathrm{w}), 656(\mathrm{~m}) .\end{array}$ \\
\hline $7 b$ & $\begin{array}{l}3235(\mathrm{~m}), 1664(\mathrm{~s}), 1613(\mathrm{w}), 1582(\mathrm{~m}), 1437(\mathrm{~m}), 1256(\mathrm{~m}), \\
1210(\mathrm{~m}), 1145(\mathrm{~m}), 1058(\mathrm{~m}), 991(\mathrm{w}), 921(\mathrm{~m}), 760(\mathrm{w}), \\
661(\mathrm{w}), 580(\mathrm{w}), 445(\mathrm{w}) .\end{array}$ \\
\hline $7 c$ & $\begin{array}{l}3235(\mathrm{w}), 1664(\mathrm{~s}), 1613(\mathrm{~m}), 1485(\mathrm{~m}), 1447(\mathrm{~m}), 1256(\mathrm{~m}), \\
1135(\mathrm{~m}), 1058(\mathrm{~m}), 991(\mathrm{w}), 760(\mathrm{~m}), 698(\mathrm{w}), 661(\mathrm{w}), \\
580(\mathrm{w}) .\end{array}$ \\
\hline $7 d$ & $\begin{array}{l}3227(\mathrm{~m}), 2970(\mathrm{~m}), 1686(\mathrm{~s}), 1654(\mathrm{~s}), 1604(\mathrm{~m}), 1425(\mathrm{~m}), \\
1294(\mathrm{w}), 1212(\mathrm{~m}), 1142(\mathrm{~m}), 1030(\mathrm{w}), 923(\mathrm{w}), 774(\mathrm{w}), \\
698(\mathrm{w}), 501(\mathrm{~m}) .\end{array}$ \\
\hline $7 e$ & $\begin{array}{l}3232(\mathrm{~m}), 2984(\mathrm{~m}), 1660(\mathrm{~s}), 1644(\mathrm{~s}), 1610(\mathrm{w}), 1508(\mathrm{~m}), \\
1432(\mathrm{~m}), 1280(\mathrm{~m}), 1202(\mathrm{~s}), 1140(\mathrm{~m}), 1051(\mathrm{~m}), 856(\mathrm{w}), \\
794(\mathrm{w}), 625(\mathrm{~m}) .\end{array}$ \\
\hline $7 f$ & $\begin{array}{l}3238(\mathrm{~m}), 2988(\mathrm{~m}), 1655(\mathrm{br}), 1612(\mathrm{~s}), 1430(\mathrm{~m}), 1412(\mathrm{~m}), \\
1260(\mathrm{~s}), 1212(\mathrm{w}), 1134(\mathrm{~m}), 1022(\mathrm{~m}), 924(\mathrm{w}), 842(\mathrm{w}), \\
780(\mathrm{w}), 629(\mathrm{w}), 524(\mathrm{w}) .\end{array}$ \\
\hline
\end{tabular}

Table 3 Elemental analyses results of CoPAs 7a-f

\begin{tabular}{|c|c|l|c|c|c|}
\hline Polymer & Formula & & $\mathrm{C} \%$ & $\mathrm{H} \%$ & $\mathrm{~N} \%$ \\
\hline $\mathbf{7 a}$ & $\mathrm{C}_{40} \mathrm{H}_{28} \mathrm{~N}_{6} \mathrm{O}_{4}$ & Calcd. & 73.16 & 4.30 & 12.80 \\
\hline & $(656.69)_{\mathrm{n}}$ & Found & 72.06 & 4.01 & 11.96 \\
\hline $\mathbf{7 b}$ & $\mathrm{C}_{38} \mathrm{H}_{22} \mathrm{~N}_{6} \mathrm{O}_{4}$ & Calcd. & 72.84 & 3.54 & 13.41 \\
\hline & $(626.62)_{\mathrm{n}}$ & Found & 72.12 & 3.42 & 13.06 \\
\hline $\mathbf{7 c}$ & $\mathrm{C}_{42} \mathrm{H}_{24} \mathrm{~N}_{6} \mathrm{O}_{4}$ & Calcd. & 74.55 & 3.57 & 12.42 \\
\hline & $(676.19)_{\mathrm{n}}$ & Found & 74.04 & 3.63 & 12.24 \\
\hline $\mathbf{7 d}$ & $\mathrm{C}_{46} \mathrm{H}_{32} \mathrm{~N}_{6} \mathrm{O}_{6}$ & Calcd. & 72.24 & 4.22 & 10.99 \\
\hline & $(764.24)_{\mathrm{n}}$ & Found & 72.21 & 3.94 & 10.11 \\
\hline $\mathbf{7 e}$ & $\mathrm{C}_{44} \mathrm{H}_{26} \mathrm{~N}_{6} \mathrm{O}_{6}$ & Calcd. & 71.39 & 3.57 & 11.44 \\
\hline & $(734.19)_{\mathrm{n}}$ & Found & 70.41 & 3.34 & 11.01 \\
\hline $\mathbf{7 f}$ & $\mathrm{C}_{48} \mathrm{H}_{28} \mathrm{~N}_{6} \mathrm{O}_{6}$ & Calcd. & 73.46 & 3.60 & 10.71 \\
\hline & $(784.21)_{\mathrm{n}}$ & Found & 72.73 & 3.18 & 10.01 \\
\hline
\end{tabular}

The solubility of CoPAs 7a-f was investigated with $0.01 \mathrm{~g}$ polymeric samples in $2 \mathrm{~mL}$ of a solvent (Table 4). All of these CoPAs were soluble in sulphuric acid and organic polar solvents such as $N, N$-dimethylformamide, $N, N$ dimethylacetamide, dimethyl sufoxide and NMP at room temperature. Some CoPAs were soluble and partially soluble on heating in pyridine and $m$-cresol, and were insoluble in solvents such as ethanol, methanol, tetrahydrofurane (THF), chloroform and water.

Table 4 Solubility of CoPAs 7a-f

\begin{tabular}{|c|c|c|c|c|c|c|}
\hline Solvent & $\mathbf{7 a}$ & $\mathbf{7 b}$ & $\mathbf{7 c}$ & $\mathbf{7 d}$ & $\mathbf{7 e}$ & $\mathbf{7 f}$ \\
\hline $\mathrm{H}_{2} \mathrm{SO}_{4}$ & + & + & + & + & + & + \\
\hline $\mathrm{DMAc}$ & + & + & + & + & + & + \\
\hline $\mathrm{DMSO}$ & + & + & + & + & + & + \\
\hline $\mathrm{DMF}$ & + & + & + & + & + & + \\
\hline $\mathrm{NMP}$ & + & + & + & + & + & + \\
\hline $\mathrm{THF}$ & $\beta-$ & $\beta-$ & $\beta-$ & $\beta-$ & $\beta-$ & $\beta-$ \\
\hline $\mathrm{MeOH}$ & - & - & - & - & - & - \\
\hline $\mathrm{EtOH}$ & - & - & - & - & - & - \\
\hline $\mathrm{CHCl}_{3}$ & - & - & - & - & - & - \\
\hline $\mathrm{H}_{2} \mathrm{O}$ & - & - & - & - & - & - \\
\hline
\end{tabular}
ture.

Solubility: $\oplus$, soluble at room temperature; - , insoluble at room tempera-

Thermal properties

The thermal properties of three samples $(\mathbf{7 c}, \mathbf{7 d}$ and $\mathbf{7 e})$ containing three different of second diacids such as adipic, fumaric and terephthalic acid were 
investigated with TGA and DTG in nitrogen atmosphere at a rate of heating of $10{ }^{\circ} \mathrm{C}$ per minute and the results are summarized in Table 5. The initial decomposition temperatures of $5 \%$ and $10 \%$ weight losses $\left(\mathrm{T}_{5}\right.$ and $\mathrm{T}_{10}$ respectively) and the char yields at $600{ }^{\circ} \mathrm{C}$ for them are summarized in Table $5 . \mathrm{T}_{5}$ for these polymers ranged from $295-340{ }^{\circ} \mathrm{C}$ and $\mathrm{T}_{10}$ for them ranged from $335-370{ }^{\circ} \mathrm{C}$, and residual weights for these polymers at $600{ }^{\circ} \mathrm{C}$ ranged from $36.03-48.02 \%$ under nitrogen atmosphere. According to the results the thermal stability of these polymers is related to the second diacid in the main chain. Thermal stability of polymer $\mathbf{7 c}$ containing terephthalic acid was higher than two other polymers, because this polymer has a rigid aromatic structure in the main chain. Also polymer containing fumaric acid $\mathbf{7 e}$ has higher thermal stability in compare to polymer $7 \mathbf{d}$ with adipic acid as second diacid.

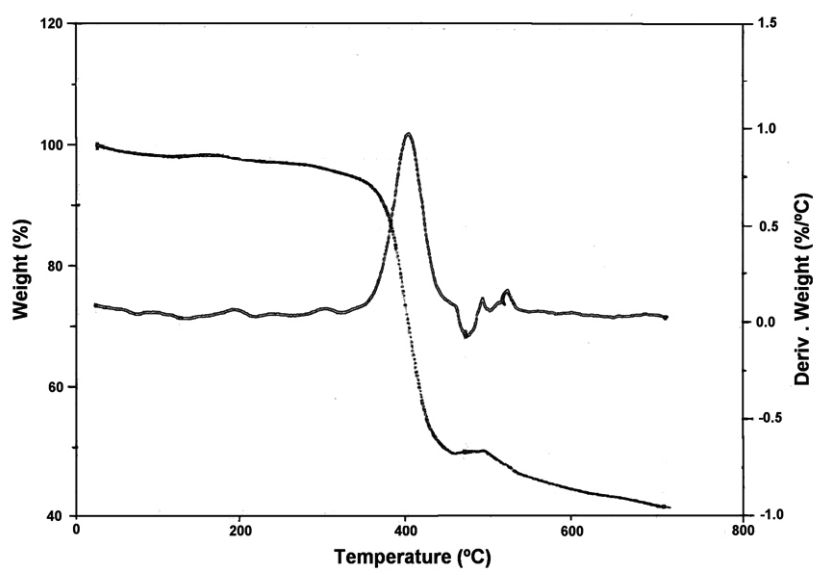

Fig.1. TGA and DTG thermogram of polymer 7c

Fig. 1. TGA and DTG thermogram of CoPA 7e

Table 5 Thermal behavior of CoPAs 7c, 7d and 7e.

\begin{tabular}{|c|c|c|c|}
\hline Polymer & $\mathrm{T}_{5}\left({ }^{\circ} \mathrm{C}\right)^{\mathrm{a}}$ & $\mathrm{T}_{10}\left({ }^{\circ} \mathrm{C}\right)^{\mathrm{b}}$ & $\begin{array}{c}\text { Char yield } \\
(\%)^{\mathrm{c}}\end{array}$ \\
\hline $\mathbf{7 c}$ & 340 & 370 & 44.93 \\
\hline $\mathbf{7 d}$ & 300 & 335 & 36.03 \\
\hline $\mathbf{7 e}$ & 295 & 350 & 48.02 \\
\hline
\end{tabular}

a,b Temperature at which 5 or $10 \%$ weight loss was recorded in TGA analysis at a heating rate of $10^{\circ} \mathrm{C} / \mathrm{min}$ in $\mathrm{N}_{2}$.

${ }^{c}$ Weight percentage of material left after TGA analysis at maximum temperature $600{ }^{\circ} \mathrm{C}$ in $\mathrm{N}_{2}$.

\section{CONCLUSION}

In this work, six new thermally stable copolyamides 7a-f were synthesized through the direct polycondensation reaction of 4,4'-azobenzenedicarboxylic acid $\mathbf{1}$ with 1,5-naphthalenediamine $\mathbf{2}$ or 3,4-diaminobenzophenone $\mathbf{3}$ in the presence of adipic acid $\mathbf{4}$, fumaric acid $\mathbf{5}$ or terephthalic acid $\mathbf{6}$ as a second diacid in a medium consisting of $N$-methyl-2-pyrrolidone, triphenyl phosphite, calcium chloride and pyridine. By introducing azo group into the polymer backbone the rigid conformation of the chains is modified increasing the solubility in polar aprotic solvents. According to the thermal analyses, the stability of these polymers is related to the second diacid in the main chain. Thermal stability of polymer $7 \mathbf{c}$ with terephthalic acid was higher than two other polymers, because this polymer has a rigid aromatic structure in the main chain. Thermal stability and solubility can make these polymers attractive for practical applications such as processable high-performance engineering plastics.

\section{REFERENCES}

1. Saxena, A.; Rao, V. L.; Prabhakaran, P. V.; Ninan, K. N. Eur. Polym. J. 39, 401, (2003).

2. Bier, G. Adv. Chem. Ser. 91, 612, (1969).

3. Yang, C. P.; Chen, Y. P.; Woo, E. M. Polymer, 45, 5279, (2004).

4. Boulares, A.; Tessier, M.; Marechal, E. Polymer, 41, 3561, (2000).

5. Ge, Z.; Yang, S.; Tao, Z.; Liu, J.; Fan, L. Polymer, 45, 3627, (2004).

6. Faghihi, Kh.; Hajibeygi, M.; Shabanian, M. Polym. Int., 59, 218, (2010).

7. Faghihi, Kh.; Hagibeygi, M. Turk. J. Chem., 31, 65, (2007).

8. Buckley, A.; Stamatof, J. B. Nonlinear optical effects in organic polymers. Dordrecht: Kluwer (1989).

9. Schab-Balcerzak, E.; Sapich B.; Stumpe, J. Polymer, 46, 45, (2005).

10. Zhang, Y.; Yu, S. J.; Wang, L.; Li, C. Chinese. Chem. Lett., 20, 235, (2009).

11. Matsunaga, D.; Tamaki, T.; Ichimura, K. J. Mater. Chem., 13, 1558, (2003).

12. Yesodha, S. K.; Sadashiva-Pillai, C. K.; Tsutsumi, N. Prog. Polym. Sci., 29, 45, (2004)

13. Buruiana, T.; Buruiana, E. C.; Airinei, A.; Grecu, I. Eur. Polym. J., 37, 343, (2001).

14. Faghihi, Kh.; Hagibeygi, M. Eur. Polym. J., 39, (2003). 